\title{
Study on the Power-Frequency Waves Distribution Characteristics for Half-Wavelength Transmission Lines Based on the Frequency-Length Factor
}

\author{
Chang Chen $\mathbb{D}^{1},{ }^{1}$ Xiaoyang Ma $\mathbb{D}^{1},{ }^{1}$ Honggeng Yang, ${ }^{1}$ Weikang Wang, ${ }^{2}$ and Yilu Liu ${ }^{2}$ \\ ${ }^{1}$ College of Electrical Engineering, Sichuan University, Chengdu 610065, China \\ ${ }^{2}$ Department of Electrical Engineering and Computer Science, The University of Tennessee, Knoxville, Tennessee 37996, USA \\ Correspondence should be addressed to Xiaoyang Ma; mxy_scu@163.com
}

Received 16 August 2019; Accepted 10 December 2019; Published 27 February 2020

Academic Editor: Qiuye Sun

Copyright (c) 2020 Chang Chen et al. This is an open access article distributed under the Creative Commons Attribution License, which permits unrestricted use, distribution, and reproduction in any medium, provided the original work is properly cited.

\begin{abstract}
To analyze the distribution characteristics of voltage and current along half-wavelength transmission lines (HWTLs) in the cases with or without short circuit in the steady state, the method based on the frequency-length factor (FLF) for lossy lines is proposed. Firstly, according to the pole condition of the FLF, the distribution characteristics of power-frequency waves along HWTLs are analyzed. Then, the comprehensive effects of the system parameters and fault resistance are explored, revealing the mechanism of the power-frequency resonance caused by nonmetallic short circuit. Meanwhile, unbalanced short-circuit fault is studied by exploiting additional impedance. The results show that the distribution of the maximum value of power-frequency resonance voltage is related to the system parameters but not to the fault impedance. When a HWTL is short circuited at $2640 \mathrm{~km} \sim 2930 \mathrm{~km}$, the resonance voltage can reach to $21 \mathrm{p}$.u. In relation to symmetrical short circuit, the resonance voltage appears at $1469 \mathrm{~km}$ from the short-circuit point, while the position moves towards the short-circuit point with the increase of additional impedance in asymmetrical short-circuit conditions. Additionally, the model theoretically proves that the power-frequency overvoltage induced by short circuit does not appear on a line whose length is less than $1469 \mathrm{~km}$. Finally, cases are studied on PSCAD to verify the accuracy of the model.
\end{abstract}

\section{Introduction}

Half-wavelength power transmission refers to the longdistance three-phase AC transmission technology. The electrical distance of a half-wave length transmission line (HWTLs) is close to half of the power-frequency wavelength ( $3000 \mathrm{~km}$ for $50 \mathrm{~Hz}$ systems and $2600 \mathrm{~km}$ for $60 \mathrm{~Hz}$ systems) [1-4]. Compared with HVDC lines [5-7] or highly compensated AC lines [8], half-wavelength power transmission technology has an advantage with no requirement of compensation, which may be the most economical solution for ultra-long distance power transmission [9-11]. Besides, HWTLs have strong transmission capacity and excellent voltage stability. Therefore, many relative research studies have been carried out by several countries including China and Russia [12, 13]. For example, in order to deliver large hydropower to load centers, Brazil has operated detailed research and simulation calculation on half-wavelength transmission technology [14, 15]. Korea investigates the feasibility of transmitting the water electricity from Siberia by means of HWTLs [16]. Developing clean energy has become an unavoidable path for China and even the whole world $[17,18]$. To deliver western wind power to the eastern load center, a lot of research on HWTLs has been carried out in China recently. Due to the development of global energy interconnection in recent years, half-wavelength power transmission has again attracted wide attention worldwide $[19,20]$.

The distribution of power-frequency voltage and current along the transmission line is the premise to ensure the safety of the electrical equipment and the stable operation of the system. At present, copious research studies have been conducted to discuss the characteristics for HWTLs in the steady state [21-24]. Meanwhile, some investigations have also been carried out for the distribution of the powerfrequency voltage and current on HWTLs after short circuit. 
However, most of these analyses either rely on simulation or neglect line loss, making them unable to give a deep insight into the mechanism [24]. Zhang et al. [25] proposed an approach to find out the location feature of power frequency along HWTLs after short circuit. However, it focused on the symmetrical fault and neglected the fault resistance. Besides, it also probed for the characteristics for other long-distance transmission lines. But the results were concluded by software simulation, lacking theoretical proof. On the research foundation above, the asymmetric short-circuit fault was analyzed in [26]. However, rather than considering the comprehensive influence of various parameters on transmission characteristics, each impact parameter was only analyzed as a single variable. In brief, the mechanism of the comprehensive influence of the parameters, i.e., system parameters and fault condition, on distribution characteristics is not clear and visible, which need a further excavation.

Based on the frequency-length factor (FLF), the model of power-frequency voltage and current distribution along lines considering line loss is deduced in this paper. Based on the pole distribution condition of the FLF, the distribution characteristics of steady-state power-frequency voltage and current on HWTLs are firstly analyzed. In this part, the effect of the active power and power factor on the distribution characteristics are obtained. Then, the powerfrequency resonance mechanism after short-circuit fault in the steady state is also discussed. The proposed model considers both the system operating parameters and the fault conditions, making it possible to understand the mechanism of power-frequency resonance. Additionally, the characteristics of power-frequency resonance for other long-distance transmission lines are also proved theoretically. Comparison between the calculation model and the simulation results on PSCAD and other reliable software is made to verify the accuracy of the model and the theoretical conclusions.

The current paper is structured as follows. Section 2 proposes the calculation models of the power-frequency waves (voltage and current) distribution on lossy lines based on the FLF. Section 3 discusses the distribution characteristics of steady-state power-frequency waves without the fault. By using the similar approach as Section 2, Section 4 proposes the models for the distribution of steady-state power-frequency waves on HWTLs with short-circuit fault occurring. Meanwhile, the distribution features are obtained. Section 5 gives a theoretical verification of other long-distance transmission lines, while Section 6 provides several case studies and discussions, and the final section concludes.

\section{Transmission Model Based on the Frequency- Length Factor Theory}

2.1. Frequency-Length Factor. The simplified structure and model of ultra-high voltage power systems with a longdistance $\mathrm{AC}$ transmission line are shown in Figure 1. $Z_{\mathrm{L}}$ is the load impedance, $S=P+\mathrm{i} Q$ is the apparent power of the load, and $P$ and $Q$ are the active power and reactive power, respectively.

The line is divided into two distributed-parameter models connected in series to obtain the distribution characteristics of voltage and current on it, as shown in Figure 1(b). The two-port network of a transmission line can be expressed as $\left[U_{\mathrm{M}}, I_{\mathrm{M}}\right]^{T}=C^{-1}\left[U_{\mathrm{S}}, I_{\mathrm{S}}\right]^{T}$, where $U_{\mathrm{S}}$ and $I_{\mathrm{S}}$ are the voltage and current of the sending end (node $S$ ), respectively. $U_{\mathrm{M}}$ and $I_{\mathrm{M}}$ are the voltage and current of the measuring point (Node $\mathrm{M}$ ) which is at a distance of $l \mathrm{~km}$ from node $\mathrm{S}$. $C$ is the T-parameter matrix of the transmission line, of which the inverse matrix is

$$
C^{-1}=\left[\begin{array}{cc}
\operatorname{ch}(\gamma l) & -Z_{\mathrm{C}} \operatorname{sh}(\gamma l) \\
-\frac{\operatorname{sh}(\gamma l)}{Z_{\mathrm{C}}} & \operatorname{ch}(\gamma l)
\end{array}\right],
$$

where $\gamma=\alpha+i \beta$ is the propagation constant, $\alpha$ and $\beta$ are the attenuation constant and the phase shift constant of the line, respectively, and $Z_{\mathrm{C}}=R_{\mathrm{C}}+i X_{\mathrm{C}}$ is the characteristic impedance.

Equation (1) contains hyperbolic functions with complex variables $\gamma l=\alpha l+i \beta l$, where $D_{1}=\alpha l$ and $\mu_{1}=\beta l$ reflect the change of amplitude and phase in transmission characteristics, respectively. $\mu_{1}$ is called the frequency-length factor (FLF), which is related to the product of frequency and line length [27].

The hyperbolic function in equation (1) can be expressed by the FLF as

$$
\left\{\begin{array}{l}
\operatorname{ch}(\gamma l)=\operatorname{ch} D_{1} \cos \mu_{1}+i \operatorname{sh} D_{1} \sin \mu_{1} \\
\operatorname{sh}(\gamma l)=\operatorname{sh} D_{1} \cos \mu_{1}+i \operatorname{ch} D_{1} \sin \mu_{1}
\end{array}\right.
$$

Equation (1) is expanded into a trigonometric function of the FLF in equation (2). Since it is technically simple to obtain the pole distribution of trigonometric functions, the transmission characteristics can be analyzed with the aid of the pole distribution feature of the FLF.

\subsection{Equivalent Transmission Model for Voltage Transmission.} In Figure 1, the relationship between the voltage and the current of node $M$ is

$$
U_{\mathrm{M}}=I_{\mathrm{M}} \times Z_{\mathrm{M}}
$$

$Z_{\mathrm{M}}$ is the equivalent impedance seen from node $M$ to node $R$ (the receiving end), which can be simplified as

$$
Z_{\mathrm{M}}=Z_{\mathrm{C}}\left[\frac{n \cdot \operatorname{sh}\left(\gamma l_{2}\right)+\operatorname{ch}\left(\gamma l_{2}\right)}{\operatorname{sh}\left(\gamma l_{2}\right)+n \cdot \operatorname{ch}\left(\gamma l_{2}\right)}\right],
$$

where $n=Z_{\mathrm{c}} / Z_{\mathrm{L}}, l_{2}=L-l$ is the length between node $\mathrm{M}$ and $\mathrm{R}$, and $L$ is the total length of the line.

Since $\left(Z_{\mathrm{L}}=V^{2}\right) /\left(S^{*}\right)$, it can be obtained that $n=a-i b$, $a=Z_{\mathrm{C}} P / V^{2}, \quad b=Z_{\mathrm{C}} Q / V^{2}=a \cdot \tan \theta$, and $|n|=\sqrt{a^{2}+b^{2}}=$ $Z_{C}|S| / V^{2} . V$ is the power-frequency voltage. $\theta$ is the power factor angle, which is positive when the load is inductive and capacitive otherwise. 


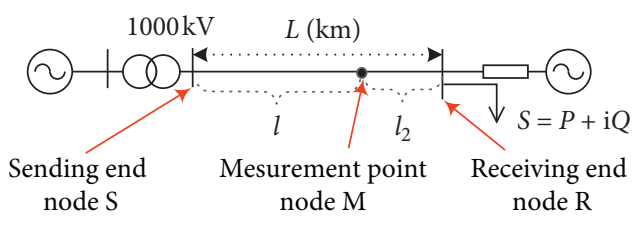

(a)

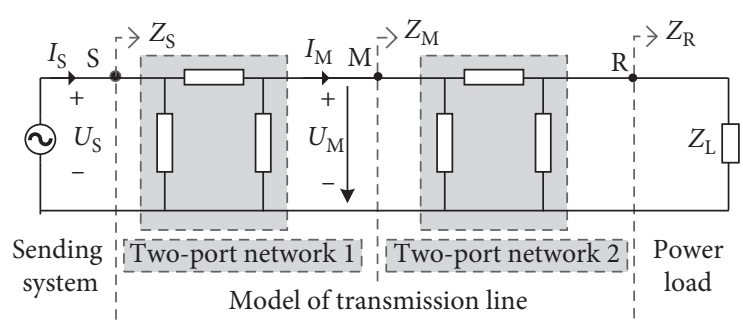

(b)

Figure 1: The simplified model of UHVAC power systems: (a) structure; (b) model.

Substituting equation (3) (4) into equation (1), the voltage transfer function between the input source at node $S$ and output response at node $\mathrm{M}$ can be written as

$$
H_{\mathrm{u}}=\frac{U_{\mathrm{M}}}{U_{\mathrm{S}}}=\frac{1}{\operatorname{ch}(\gamma l)+\left(Z_{\mathrm{C}} / Z_{\mathrm{M}}\right) \operatorname{sh}(\gamma l)}
$$

Simplifying equation (5) by equation (4), there is

$$
H_{\mathrm{u}}=\frac{n \cdot \operatorname{sh}\left(\gamma l_{2}\right)+\operatorname{ch}\left(\gamma l_{2}\right)}{n \cdot \operatorname{sh}(\gamma L)+\operatorname{ch}(\gamma L)} .
$$

It can be seen that the structure of the numerator and denominator in equation (6) are similar to each other. Therefore, we construct an intermediate function, $f_{\mathrm{u}}\left(\mu_{x}\right)=n \cdot \operatorname{sh}(\gamma x)+\operatorname{ch}(\gamma x)$, which can be simplified by equation (2) as

$$
\begin{aligned}
f_{\mathrm{u}}\left(\mu_{x}\right)= & {\left[\left(\operatorname{ch} D_{x}+a \operatorname{sh} D_{x}\right) \cos \mu_{x}+b \operatorname{ch} D_{x} \sin \mu_{x}\right] } \\
& +i\left[\left(\operatorname{sh} D_{x}+a \operatorname{ch} D_{x}\right) \sin \mu_{x}-b \operatorname{sh} D_{x} \cos \mu_{x}\right],
\end{aligned}
$$

where $\mu_{x}=\beta x$. By introducing an auxiliary angle $\varphi$, the magnitude of $f_{\mathrm{u}}\left(\mu_{x}\right)$ can be expressed as

$$
f_{\mathrm{u}}\left(\mu_{x}\right)=\left|f_{\mathrm{u}}\left(\mu_{x}\right)\right|=\sqrt{A_{\mathrm{u}} \sin \left(2 \mu_{x}+\varphi\right)+B_{\mu_{x}}}
$$

where $A_{\mathrm{u}}=\operatorname{sgn} b \cdot A$. $\operatorname{sgn} b$ is the signal function of $b$, and there is $\operatorname{sgn} b=\operatorname{sgn} \theta \cdot \operatorname{sgn} b=1$ when the load is inductive $(\theta>0)$. And $\operatorname{sgn} b=-1$ when $\theta<0 . \operatorname{sgn} b=0$ when the load is a pure resistance. $A=\sqrt{\left(1-|n|^{2}\right)^{2} / 4+b^{2}}$, while $B_{\mu_{x}}$ and $\varphi$ are

$$
\left\{\begin{array}{l}
B_{\mu_{x}}=\left[\frac{\left(1+|n|^{2}\right)}{2}\right] \times \operatorname{ch}\left(2 D_{x}\right)+a \operatorname{sh}\left(2 D_{x}\right), \\
\varphi=\arctan \left[\frac{\left(1-|n|^{2}\right)}{(2 b)}\right]
\end{array}\right.
$$

$\varphi$ in equation $(9)$ is $\pi / 2$ and $-(\pi / 2)$ when $b \longrightarrow 0$ and $\infty$, respectively. Otherwise, $-\pi / 2<\varphi<\pi / 2$.

The magnitude of $H_{\mathrm{u}}$ is numerically equal to the per unit value of voltage. That is, $U_{\mathrm{M}}^{*}=\left|H_{\mathrm{u}}\right|$ (p.u.). Therefore, substituting equation (8) into (6), it can be obtained that

$$
U_{\mathrm{M}}^{*}=\frac{\sqrt{A_{\mathrm{u}} \sin \left(2 \mu_{l_{2}}+\varphi\right)+B_{\mu_{l_{2}}}}}{\sqrt{A_{\mathrm{u}} \sin \left(2 \mu_{\mathrm{L}}+\varphi\right)+B_{\mu_{L}}}}=\frac{f_{\mathrm{u}}\left(\mu_{l_{2}}\right)}{f_{\mathrm{u}}\left(\mu_{L}\right)} .
$$

2.3. Equivalent Transmission Model for Current Transmission. The current transfer function at any point on a long-distance transmission line can also be derived by the similar method as that in Section 2.1, as follows:

$$
H_{i}=\frac{I_{\mathrm{M}}}{U_{\mathrm{S}}}=\frac{1}{\left|Z_{\mathrm{C}}\right|} \cdot \frac{\operatorname{sh}\left(\gamma l_{2}\right)+n \cdot \operatorname{ch}\left(\gamma l_{2}\right)}{n \cdot \operatorname{sh}(\gamma L)+\operatorname{ch}(\gamma L)} .
$$

Similarly, constructing an intermediate function $f_{i}\left(\mu_{x}\right)=\operatorname{sh}(\gamma x)+n \cdot \operatorname{ch}(\gamma x)$. Then, simplifying the magnitude of $f_{i}\left(\mu_{x}\right)$, the current on the line can be expressed as

$$
\begin{aligned}
I_{\mathrm{M}} & =\frac{\left|U_{\mathrm{S}}\right|}{\left|Z_{\mathrm{C}}\right|} \cdot \frac{\sqrt{A_{i} \sin \left(2 \mu_{l_{2}}+\varphi\right)+B_{\mu_{2}}}}{\sqrt{A_{\mathrm{u}} \sin \left(2 \mu_{\mathrm{L}}+\varphi\right)+B_{\mu_{\mathrm{L}}}}} \\
& =\frac{\left|U_{1}\right|}{\left|Z_{\mathrm{C}}\right|} \cdot \frac{f_{i}\left(\mu_{l_{2}}\right)}{f_{\mathrm{u}}\left(\mu_{\mathrm{L}}\right)},
\end{aligned}
$$

where $A_{i}=-\operatorname{sgn} b \sqrt{\left(1-|n|^{2}\right)^{2} / 4+b^{2}}=-A_{\mathrm{u}}$.

2.4. The Distribution Characteristics of FLF. Equations (10) and (12) simplify the transmission coefficients into trigonometric functions verifying with the FLF. While $B_{\mu_{x}}$ also contains the product of frequency and length, it changes little at the power frequency $f_{0}$. Therefore, $B_{\mu_{x}}$ is considered as a parameter that has no effect on the pole distribution of the FLF.

The pole conditions of $f_{\mathrm{u}}\left(\mu_{x}\right)$ and $f_{i}\left(\mu_{x}\right)$ can be expressed as follows:

$$
\begin{aligned}
& \mu_{x}=-\frac{\varphi}{2}-\frac{\pi}{2}+N \pi, \\
& \mu_{x}=-\frac{\varphi}{2}+\frac{\pi}{2}+N \pi,
\end{aligned}
$$

where $N$ is the integer. When $\theta>0$, there is $A_{\mathrm{u}}>0$; thus, equations (13) and (14) are the minimum and maximum conditions of $f_{\mathrm{u}}\left(\mu_{x}\right)$, respectively. Meanwhile, since $A_{i}=-A_{\mathrm{u}}<0$, they are the maximum and minimum conditions of $f_{i}\left(\mu_{x}\right)$, respectively. The pole distribution conditions are contrary to the above when $\theta<0$. Moreover, when $\theta=0$, there is $A_{\mathrm{u}}=A_{i}=0$. Accordingly, the transmission of the power-frequency voltage and current is no longer distributed as trigonometric functions of the FLF.

Combining with the position (in numerator or denominator) of $f_{\mathrm{u}}\left(\mu_{x}\right)$ or $f_{i}\left(\mu_{x}\right)$ in the fractional functions, the extreme conditions of $U_{\mathrm{M}}^{*}$ and $I_{\mathrm{M}}$ can be discussed. For 
example, when the load is inductive, the analysis of the extreme value of voltage distribution on a line is translated to a problem of figuring out the polar condition of $f_{\mathrm{u}}\left(\mu_{x}\right)$ as the numerator of $U_{\mathrm{M}}^{*}$. Therefore, equation (14) is the maximum condition of $U_{M}^{*}$, while equation (13) is its minimum condition. When discussing the influence of line length $(L)$ on voltage transmission, the pole condition of $f_{\mathrm{u}}\left(\mu_{x}\right)$ as the denominator of $U_{\mathrm{M}}^{*}$ is aimed to be found out. Therefore, equations (13) and (14) are the maximum and minimum conditions, respectively.

\section{Distribution Characteristics of Power- Frequency Current and Voltage on HWTLs in Steady State}

3.1. Feature of Voltage Distribution. According to the pole distribution condition of the FLF, the maximum voltage on the line $\left(U_{\mathrm{m}}^{*}\right)$ and the distance $\left(l_{\mathrm{m}}\right)$ between $U_{\mathrm{m}}^{*}$ and node $S$ under various operation modes can be obtained. Moreover, the characteristics of $U_{\mathrm{m}}^{*}$ and $l_{\mathrm{m}}$ variating with load conditions can be analyzed, as shown in Figure 2(a). The following is the concrete analysis approach.

3.1.1. $\theta=0$. Assume the load power is $P=k P_{n}$, where $P_{n}$ is the natural power of the line. When $\theta=0$, there is $b=0$, thus $|n|=k$. Accordingly, $A_{\mathrm{u}}=\left.|| n\right|^{2}-1 \mid / 2$ and $B_{\mu_{x}}=\left(|n|^{2}+1\right)$. $\operatorname{ch}\left(2 D_{x}\right) / 2+\operatorname{ash}\left(2 D_{x}\right)$.

When $|n|=1$, which means that the natural power is transmitted on the line. Thus, $A_{\mathrm{u}}=0$, and $B_{\mu_{x}}=e^{2 D_{x}}$. Therefore, the distribution function of the power-frequency voltage on the line can be expressed as $U_{\mathrm{M}}^{*}=e^{-2 \alpha l}=e^{-2 D_{l}}$. That is to say that the voltage distribution on the line attenuated slowly by the natural exponent.

When $|n|>1$, there is $A_{\mathrm{u}}>0$ and $\varphi=-90^{\circ}$. From the extreme condition equation (14), it can be obtained that $U_{\mathrm{m}}^{*}$ occurs at $\mu=\pi / 4$, which is the midpoint of the HWTL. Meanwhile, $a$ increases with $P$, thus $U_{\mathrm{m}}^{*}$ also increases with $P$.

When $|n|<1$, there is $\varphi=90^{\circ}$. So, $U_{\mathrm{m}}^{*}$ appears at the node $\mathrm{S}$, while the minimum value is at the midpoint of the line.

3.1.2. $\theta>0$. Equation (14) is the condition for the occurrence of the maximum voltage on the line. Combining with the range of $\varphi$, some conclusions can be obtained as follows.

When $|n|>1$, it can be obtained that $\lambda_{0} / 4<l_{\mathrm{m}}<3 / 8 \lambda_{0}$. With the increase of $P$, the parameter $a$ increases, thus decreasing $\varphi$ and resulting in a bigger $l_{\mathrm{m}}$. That is to say that $U_{\mathrm{m}}^{*}$ move towards node $\mathrm{S}$ with the increase of $P$. Moreover, because the parameter $A$ increases with $a, U_{\mathrm{m}}^{*}$ also becomes bigger with $P$. On the other hand, $b$ decreases with the increase of the load power factor $\cos \theta$. Considering that the $\cos \theta$ of a UHV system is generally greater than $0.9, \varphi$ decreases with $\cos \theta$, resulting in a smaller $l_{\mathrm{m}}$. Meanwhile, because $b$ decreases with $A, U_{\mathrm{m}}^{*}$ also decreases with $A$.
When $|n|<1$, it can be obtained in the similar way that $l_{\mathrm{m}}=3 / 8 \lambda_{0}$. Additionally, $l_{\mathrm{m}}$ increases with $P$ and $\cos \theta$, while $U_{\mathrm{m}}^{*}$ increases $P$ but decreases with $\cos \theta$. When $|n|=1$, there is $l_{\mathrm{m}}=3 / 8 \lambda_{0}$.

In summary, when the line transmits inductive reactive power, $U_{\mathrm{m}}^{*}$ appears in the second half of the line. It increases with $P$, but decreases with $\cos \theta$.

3.1.3. $\theta<0$. Similarly, according to equation (13), when $|n|>1, \lambda_{0} / 8<l_{\mathrm{m}}<\lambda_{0} / 4 . l_{\mathrm{m}}$ increases with $P$ and $\cos \theta$. When $|n|<1$, there is $0<l_{\mathrm{m}}<\lambda_{0} / 8 . l_{\mathrm{m}}$ increases with $P$, but decreases with $\cos \theta$. When $|n|=1, l_{\mathrm{m}}=\lambda_{0} / 8$. In brief, when the load is capacitive, $U_{\mathrm{m}}^{*}$ appears in the first half of the line, and the relationship between $U_{\mathrm{m}}^{*}$ and $P$ or $\cos \theta$ are the same as the condition of $\theta>0$.

3.2. Feature of Current Distribution. Using the similar method as that in Section 3.1, the impact of operation modes on the current distribution along the line is discussed. The distribution of the maximum current on the line is shown in Figure 2(b). In particular, when $\theta=0$ and $k=1$, the current transmission function is $I_{\mathrm{M}}=\left(U_{1}\right) /\left(\left|Z_{\mathrm{C}}\right|\right) e^{-2 D_{l}}$. Otherwise, it is a trigonometric function as (12).

3.3. Amplitude Feature. Based on the analysis above, $U_{\mathrm{m}}^{*}$ can be expressed as

$$
U_{\mathrm{m}}^{*}=\frac{\sqrt{A_{\mathrm{u}}+B_{\mu_{2}}}}{\sqrt{A_{\mathrm{u}} \sin (\varphi)+B_{\mu_{\mathrm{L}}}}} .
$$

It can be obtained that $A_{\mathrm{u}} \sin (\varphi)=1-|n|^{2} / 2$. In addition, $\operatorname{ch}(x)$ is expended to the Taylor series as $\operatorname{ch}\left(2 D_{\mathrm{L}}\right)=1+x^{2} / 2 !+x^{4} / 4 ! \cdots=1+o(x)$ for convenience. Accordingly, when there is a $U_{\mathrm{m}}^{*}$ on the line, it can be simplified as

$$
U_{\mathrm{m}}^{*}=\frac{|n|}{\sqrt{1+\delta}}
$$

where $\delta=\left(|n|^{2}+1\right) \cdot o\left(2 D_{L}\right) / 2$.

Similarly, $I_{m}$ can also be expressed as

$$
I_{\mathrm{m}}=\frac{\left|U_{1}\right|}{\left|Z_{C}\right|} \frac{|n|}{\sqrt{1+\delta}} .
$$

It can be seen that $U_{\mathrm{m}}^{*}$ and $I_{m}$ are both related to $|n| . U_{\mathrm{m}}^{*}$ and $I_{m}$ increases with $P$ and $Q$, which means they decrease with $|\cos \theta|$.

\section{Characteristics of Steady-State Power- Frequency Resonance for HWTLs after Short Circuit}

Figure 3 shows the system equivalent circuit when the fault point (node F) is short circuited. Taking node $\mathrm{F}$ as the demarcation point, the system is divided into the models of 


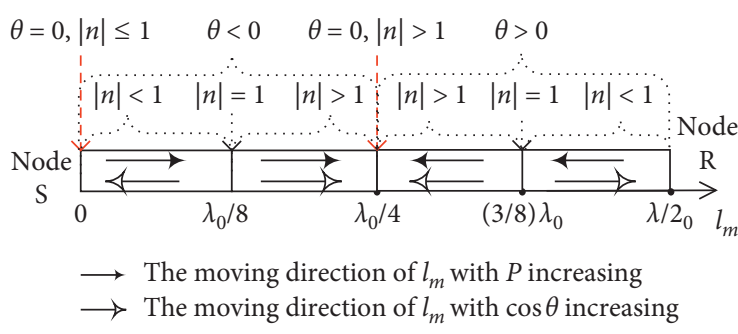

(a)

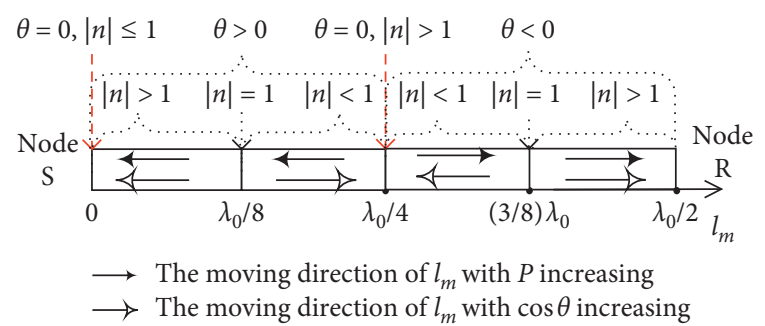

(b)

FIgURE 2: Distribution characteristics of maximum power-frequency wave along the line: (a) voltage; (b) current.

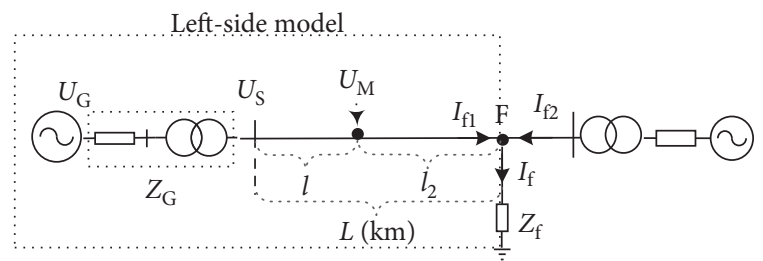

FIGURE 3: Diagram of three-phase short circuit of the research system.

the left side and right side. Since the calculation models of both sides are the same, it is reasonable to analyze the leftside model merely.

The one-side model of the system in Figure 3 is similar to that shown in Figure 1(a). Therefore, equation (3) (12) can also be derived in short-circuit analysis, where $L$ and $l_{2}$ have different definitions in short-circuit analysis. $L$ represents the distance between node $\mathrm{F}$ and $\mathrm{S}$, and $l_{2}$ is the length between node $\mathrm{F}$ and $\mathrm{M}$.

There is a local steady-state maximum voltage and shortcircuit current on the line after the fault, which is $l_{2 \mathrm{~m}}$ kilometers away from node $F$. In addition, the local maximum voltage and current vary with node $\mathrm{F}$. The fault point that makes them reach the maximum value $\left(U_{\mathrm{fm}}^{*}\right.$ and $\left.I_{\mathrm{fm}}\right)$ is called "the most serious short-circuit point," which is at a distance of $L_{\mathrm{m}}$ from node $\mathrm{S}$.

4.1. Calculation Models. Considering the effect of system parameters and fault conditions on the distribution of power-frequency voltage simultaneously, there is

$$
\begin{aligned}
\frac{U_{\mathrm{S}}}{U_{\mathrm{G}}} & =\frac{Z_{\mathrm{S}}}{Z_{\mathrm{S}}+Z_{\mathrm{G}}}, \\
Z_{\mathrm{S}} & =Z_{\mathrm{C}}\left[\frac{n \cdot \operatorname{sh}(\gamma L)+\operatorname{ch}(\gamma L)}{\operatorname{sh}(\gamma L)+n \cdot \operatorname{ch}(\gamma L)}\right],
\end{aligned}
$$

where $n=Z_{\mathrm{C}} / Z_{\mathrm{f}} . Z_{\mathrm{G}}$ is the total impedance of the sending system with generators and transformers included. $Z_{\mathrm{f}}$ represents different fault conditions. It is the fault resistance for symmetric short-circuit analysis, or the additional impedance to simulate asymmetric short circuit.

Combining equations (6), (18), and (19), it can be obtained that

$$
U_{\mathrm{Mf}}^{*}=\frac{U_{\mathrm{M}}}{U_{\mathrm{G}}}=\frac{\operatorname{sh}\left(\gamma l_{2}\right)+n \cdot \operatorname{ch}\left(\gamma l_{2}\right)}{(n+m) \operatorname{sh}(\gamma L)+(n m+1) \operatorname{ch}(\gamma L)},
$$

where $m=Z_{\mathrm{G}} / Z_{\mathrm{C}}$.

Similarly, the short-circuit current can be obtained as

$$
I_{\mathrm{f} 1}=\frac{U_{\mathrm{G}}}{Z_{\mathrm{f}}} \cdot \frac{1}{(n+m) \operatorname{sh}(\gamma L)+(n m+1) \operatorname{ch}(\gamma L)} .
$$

Since $Z_{\mathrm{G}}=i X_{\mathrm{G}}$ is mainly a inductance in practical engineering, it can be assumed that $m=i d$ and $d>0$. Using the similar method as that in Section 1.2, it can be obtained that

$$
U_{\mathrm{Mf}}^{*}=\frac{f_{\mathrm{u}}\left(\mu_{l_{2}}\right)}{g\left(\mu_{L}\right)}
$$

where $f_{\mathrm{u}}\left(\mu_{l_{2}}\right)$ is the molecular partial of equation (10):

$$
\begin{aligned}
g\left(\mu_{\mathrm{L}}\right) & =\sqrt{A_{\mathrm{g}} \sin \left(2 \mu_{\mathrm{L}}+\varphi_{\mathrm{g}}\right)+B_{\mu_{\mathrm{L}} \mathrm{g}}} \\
A_{\mathrm{g}} & =\sqrt{\left[\frac{\left.\left(|n|^{2}-1\right)\left(d^{2}-1\right)+4 b d\right]^{2}}{2}+\left(|n|^{2} d-b d^{2}+b-d\right)^{2},\right.} \\
B_{\mu_{\mathrm{L}} \mathrm{g}} & =a\left(d^{2}+1\right) \operatorname{sh}\left(2 D_{\mathrm{L}}\right)+\frac{\left(|n|^{2}+1\right)\left(d^{2}+1\right)}{2} \operatorname{ch}\left(2 D_{\mathrm{L}}\right), \\
\varphi_{\mathrm{g}} & =\arctan \left[\frac{\left(1-d^{2}\right)\left(1-|n|^{2}\right)+4 b d}{2\left(|n|^{2} d-b d^{2}+b-d\right)}\right] .
\end{aligned}
$$

In the similar way, the short-circuit current can be simplified to

$$
I_{\mathrm{f} 1}=\frac{U_{\mathrm{G}}}{Z_{\mathrm{f}}} \cdot \frac{1}{g\left(\mu_{\mathrm{L}}\right)} \text {. }
$$

4.2. Characteristics of Symmetrical Short-Circuit Fault. In this section, the comprehensive effect of the sending system parameter and the fault condition are represented by Zf. $Z_{\mathrm{f}}=R_{\mathrm{f}}$ on transmission characteristics is analyzed for symmetrical grounding short circuit.

Given that the real part of $Z_{\mathrm{C}}$ is usually much larger than that of the imaginary part in engineering, it can be considered that $a>0$ and $b$ is positive but very small, which is neglected in analysis. Meanwhile, according to the 
parameters of the UHVAC systems in actual demonstration project $[28,29]$, the system impedance under small and large operation mode are $Z_{\mathrm{G}}=i 0.07$ p.u. and $Z_{\mathrm{G}}=i 0.002$ p.u., respectively. The base voltage and base capacity of the system are $U_{\mathrm{b}}=1050 \mathrm{kV}$ and $S_{\mathrm{b}}=1000 \mathrm{MVA}$, respectively. In addition, for the reason that the fault resistance of UHV systems is generally less than $50 \Omega$ after three-phase short circuit [30], it can be considered that $d<1$, a $>1$, and $d \ll a$. Therefore, it can be obtained that

$$
\left\{\begin{array}{l}
A_{\mathrm{u}}=\frac{a^{2}-1}{2} \\
B_{\mu_{2}}=\frac{a^{2}+1}{2} \operatorname{ch}\left(2 D_{l_{2}}\right)+a \operatorname{sh}\left(2 D_{l_{2}}\right), \\
\varphi=-\frac{\pi}{2} \\
A_{\mathrm{g}}=\left(d^{2}+1\right) \frac{a^{2}-1}{2}, \\
B_{\mu_{\mathrm{L}} \mathrm{g}}=\left(d^{2}+1\right)\left[\frac{\left(a^{2}+1\right)}{2} \operatorname{ch}\left(2 D_{\mathrm{L}}\right)+a \sin \left(2 D_{\mathrm{L}}\right)\right] \\
\varphi_{\mathrm{g}}=\arctan \left(\frac{d}{2}-\frac{1}{2 d}\right) .
\end{array}\right.
$$

By the simplification above, the distribution characteristics of power-frequency voltage and short-circuit current on the line after the fault are expressed by functions containing parameters $a$ and $d$. This can be used to analyze the comprehensive influence of both fault resistance $R_{\mathrm{f}}$ and system impedance $Z_{\mathrm{G}}$ on short-circuit characteristics intuitively.

\subsubsection{Location Characteristics of the Maximum Short-Circuit} Voltage along the Line. The condition for the maximum value of the calculation model equation (22) is $\mu_{l_{2 m}}=(\pi / 2)+N \pi$. It can be obtained that $l_{2 \mathrm{~m}}=\lambda_{0} / 4$ when $\left(\lambda_{0} / 4\right)<L<\left(\lambda_{0} / 2\right)$, while $l_{2 \mathrm{~m}}=L$ when $L<\lambda_{0} / 4$. That is to say, the position that the short-circuit voltage reaches maximum on the line is independent of the sending system parameters and the fault resistance. It is at the distance of $\lambda_{0} / 4$ from node $\mathrm{F}$ when some point of the second half of the line is shortcircuited. Otherwise, it is at node S.

\subsubsection{Distribution Characteristics of the Most Serious Short Circuit}

(1) Location Feature. As can be seen from equation (25), $\varphi_{\mathrm{g}}$ is only related to $d$ but not to $a$. That is, the location of the most serious fault point is only depended on the sending system parameters but not on the fault resistance. In addition, $d$ increases with $X_{\mathrm{G}}$, thus $\varphi_{\mathrm{g}}$ increases, resulting in the decrease of $L_{\mathrm{m}}$. That is, the most serious fault point move towards the midpoint of the line from the receiving end.

According to the pole distribution characteristics of $g\left(\mu_{\mathrm{L}}\right)$, it can be obtained that $L_{\mathrm{m}}=\left((3 / 4)-\left(\varphi_{\mathrm{g}} / 2 \pi\right)\right)\left(\lambda_{0} / 2\right)$.
Due to $-(\pi / 2)<\varphi_{\mathrm{g}}<(\pi / 2)$, there is $\left(\lambda_{0} / 4\right)<L_{\mathrm{m}}<\left(\lambda_{0} / 2\right)$. That is to say, the point causing the most serious three-phase short circuit is at the second half of a HWTL.

(2) Amplitude Feature. By using the same method as that in Section 3.3, the most serious short-circuit voltage $U_{\mathrm{fm}}^{*}$ and short-circuit current $I_{\mathrm{fm}}$ are simplified as

$$
\left\{\begin{array}{l}
U_{\mathrm{fm}}^{*}=\frac{1}{\sqrt{d^{2}+1}} \sqrt{\frac{a^{2}+\delta_{\lambda_{0} / 4}}{1+\delta_{L_{\mathrm{mf}}}}} \\
I_{\mathrm{fm}}=\frac{U_{\mathrm{G}}}{\left|Z_{\mathrm{C}}\right|} \frac{a}{\sqrt{\left(d^{2}+1\right)\left(1+\delta_{L_{\mathrm{mf}}}\right)}},
\end{array}\right.
$$

where $\delta_{\lambda_{0} / 4}=\left(\left(a^{2}+1\right) / 2\right) \cdot o\left(D_{\lambda_{0} / 4}\right)$ and $\delta_{L_{\mathrm{mf}}}=\left(\left(a^{2}+1\right) / 2\right)$. $o\left(D_{L_{\mathrm{mf}}}\right)$.

When $X_{\mathrm{G}}$ increases from a very small value, $\delta_{L_{\mathrm{mf}}}$ is the dominant variation, which decreases with $X_{\mathrm{G}}$. Therefore, $I_{\mathrm{fm}}$ increases with $X_{\mathrm{G}}$. After that, $d$ becomes the major variation, which increases with $X_{\mathrm{G}}$, resulting in the decrease of $U_{\mathrm{fm}}^{*}$ and $I_{\mathrm{fm}}$. In brief, $U_{\mathrm{fm}}^{*}$ and $I_{\mathrm{fm}}$ increase with $X_{\mathrm{G}}$ first, but then decrease. On the other hand, when $R_{\mathrm{f}}$ becomes larger, $I_{\mathrm{fm}}$ and $U_{\mathrm{fm}}^{*}$ decrease because of the decrease of $a$.

4.3. Characteristics of Asymmetrical Short-Circuit Fault. Asymmetrical short-circuit can be simulated by changing the additional impedance $Z_{\mathrm{f}}=i X_{\mathrm{f}}$ [31], where $b>0$ and $a=0$. Thus, it can be obtained that

$$
\left\{\begin{array}{l}
A_{\mathrm{u}}=\frac{b^{2}+1}{2}, \\
B_{\mu_{l_{2}}}=A_{\mathrm{u}} \operatorname{ch}\left(2 D_{l_{2}}\right), \\
\varphi=\arctan \left(\frac{1}{2 b}-\frac{b}{2}\right), \\
A_{\mathrm{g}}=\frac{\left(b^{2}+1\right)\left(d^{2}+1\right)}{2}, \\
B_{\mu_{\mathrm{L}}}=A_{\mathrm{uG}} \operatorname{ch}\left(2 D_{\mathrm{L}}\right), \\
\varphi_{\mathrm{g}}=\arctan \left\{\frac{1}{2}\left[\frac{(d+(1 / b))-1}{(d+(1 / b))}\right]\right\} .
\end{array}\right.
$$

4.3.1. Location Characteristics of the Maximum Short-Circuit Voltage on the Line. It can be seen from equation (27) that $\varphi$ is related to $b$ but independent of $d$. That is, the position that the short-circuit voltage reaches maximum is only related to the additional impedance $Z_{\mathrm{f}}$ but not to the sending system parameters. When $Z_{\mathrm{f}}$ decreases, $b$ increases but $\varphi$ decreases, 
TABLE 1: The information of an UHVAC transmission line.

\begin{tabular}{|c|c|}
\hline Type of wire & $8 \times$ LGJ-500/35 (with $400 \mathrm{~mm}$ between conductors in the bundle) \\
\hline Type of the ground wire & JLB20A-170 \\
\hline Information of conductor arrangement & $\begin{array}{c}\text { Distance from suspension point of upper conductor to ground: } 65 \mathrm{~m} \\
\text { Distance from suspension point of lower conductor to ground: } 45 \mathrm{~m} \\
\text { Vertical distance between suspension points of the ground wire and upper conductor: } 12 \mathrm{~m} \\
\text { Horizontal distance between upper conductor and central line: } 0 \\
\text { Horizontal distance between lower conductor and central line: } 16 \\
\text { Horizontal distance between ground wire and central line: } 14 \\
\text { Conductor sag: } 18.5 \mathrm{~m} \\
\text { Ground wire sag: } 12.5 \mathrm{~m}\end{array}$ \\
\hline Per unit length parameters & $\begin{array}{c}R_{0}=0.0081 \Omega / \mathrm{km}, X_{0}=0.2631 \Omega / \mathrm{km}, C_{0}=0.01383 \mu \mathrm{F} / \mathrm{km} \\
P_{\mathrm{n}}=4063 \mathrm{MW}, \lambda_{0} / 2=2938 \mathrm{~km}\end{array}$ \\
\hline
\end{tabular}

thus causing a larger $l_{2 \mathrm{~m}}$. In other words, the distance between the position of the maximum short-circuit voltage and the short-circuit point decreases with $Z_{\mathrm{f}}$.

Based on the pole distribution characteristics of $f_{\mathrm{u}}\left(\mu_{l_{2}}\right)$, there is $l_{2 \mathrm{~m}}=(1 / 4-\varphi / 2 \pi) \lambda_{0} / 2$. Therefore, it can be obtained that $0<l_{2 \mathrm{~m}}<\left(\lambda_{0} / 4\right)$ when $\left(\lambda_{0} / 4\right)<L<\left(\lambda_{0} / 2\right)$, while $l_{2 \mathrm{~m}}=L$ when $L<\left(\lambda_{0} / 4\right)$.

4.3.2. Location Characteristics of the Most Serious Fault. It can be seen from equation (27) that $\varphi_{\mathrm{g}}$ is related to both $d$ and $b$. In addition, the increase of $X_{\mathrm{G}}$ (or $Z_{\mathrm{f}}$ ) enlarges $d$ (or reduces $b$ ). Hence, $\varphi_{\mathrm{g}}$ becomes larger, resulting in a bigger $L_{\mathrm{m}}$. In other words, the distance between the most-serious fault point and node $S$ moves towards the midpoint of the line from node $\mathrm{R}$ with the increase of $X_{\mathrm{G}}$ and $Z_{\mathrm{f}}$.

It can be obtained in the same way as (1) in Section 4.2.2 that $\lambda_{0} / 4<L_{\mathrm{m}}<\lambda_{0} / 2$. That is, the most serious point of three-phase short circuit occurs in the second half of the HWTL. The power-frequency voltage and short-circuit current along the line reach to maximum when such point is short circuited.

\section{Characteristics of Steady-State Power- Frequency Resonance for Long-Distance Transmission Lines after Fault}

From the abovementioned analysis, it can be seen that there is $0<\mu_{L}<\pi / 2$ when $0<L<\lambda_{0} / 4$. According to the pole distribution condition of $f_{\mathrm{u}}\left(\mu_{l_{2}}\right)$, the maximum voltage $U_{\mathrm{fm}}^{*}$ along the line appears at node S, that is, $l_{2}=L$ and $\mu_{l_{2}}=\mu_{\mathrm{L}}$. Hence, the most-serious short-circuit voltage can be expressed as $U_{\mathrm{fm}}^{*}=f_{\mathrm{u}}\left(\mu_{\mathrm{L}}\right) / g\left(\mu_{\mathrm{L}}\right)$.

In order to analyze $U_{\mathrm{fm}}^{*}$, construct a function as $F\left(\mu_{\mathrm{L}}\right)=\left[g\left(\mu_{\mathrm{L}}\right)\right]^{2}-\left[f_{\mathrm{u}}\left(\mu_{\mathrm{L}}\right)\right]^{2}$. By calculating the derivative of $F\left(\mu_{\mathrm{L}}\right)$, it can be obtained that $F\left(\mu_{\mathrm{L}}\right)$ increases monotonously or increases first but then decreases. Therefore, it reaches minimum when $\mu_{\mathrm{L}}=0$ or $\mu_{\mathrm{L}}=\lambda_{0} / 4$. Since $F(0)$, $F(\pi / 2), f_{\mathrm{u}}\left(\mu_{\mathrm{L}}\right)$, and $\mathrm{g}\left(\mu_{\mathrm{L}}\right)$ are all larger than 0 , it can be easily obtained that $\mathrm{g}\left(\mu_{\mathrm{L}}\right)>f_{\mathrm{u}}\left(\mu_{\mathrm{L}}\right)$. Therefore, there is $U_{\mathrm{fm}}^{*}<1$. That is to say, for a line with length less than $\lambda_{0} / 4$, power-frequency resonance cannot appear along the line after short circuit, and there is no overvoltage.

\section{Case Study and Discussions}

6.1. The Distribution Characteristic of Voltage and Current on HWTLs. A point-to-point power system with a HWTL is built in PSCAD, as shown in Figure 1, where the traveling wave Bergeron model of the transmission line is chosen. This model is based on the distributed LC parameters and lumped resistance. It represents the inductance and capacitance of the $\pi$ segments in a distributed way rather than lumped parameters and uses the lumped resistance to reflect line loss. Therefore, the Bergeron model in PSCAD can accurately simulate transmission lines at the power frequency $f_{0}$ and is suitable for the cases related to the power flow at $f_{0}$ [32]. The studied HWTL is an existing transmission line of the UHV power system in China, where the parameters are calculated and shown in Table 1 .

Figure 4 shows the results of maximum power-frequency voltage, current, and their distribution characteristics under different operation modes. The error between the results of simulation and the proposed model calculation is tiny, which is less than $0.15 \%$. That is to say that the method presented in this paper can accurately analyze the distribution characteristics of power-frequency voltage and current in the steady state. It can be seen from Figure 4 that the distribution characteristics of $U_{\mathrm{m}}^{*}$ and $I_{\mathrm{m}}$ are consistent with Figure 2 and the conclusions in Section 3.3. When $\theta=0$ $(\cos \theta=1), U_{\mathrm{m}}^{*}$ appears at the sending bus when a power of less than $4063 \mathrm{MW}$ is transmitted or at the midpoint of the line $(l=1469 \mathrm{~km})$ when the transmitted power is more than $4063 \mathrm{MW}$. The position of $I_{\mathrm{m}}$ is opposite to that of $U_{\mathrm{m}}^{*}$. It occurs at $l=1469 \mathrm{~km}$ when $P<4063 \mathrm{MW}$ or at the sending bus when $P>4063 \mathrm{MW}$. Moreover, $U_{\mathrm{m}}^{*}$ increases with $P$, while $I_{\mathrm{m}}$ decreases with it. Given that the voltage on the line in an actual UHVAC power system cannot exceed 1.2 p.u. for the safety operation [33], it is suggested that the active power of the UHV system with HWTLs should be less than $1.25 P_{\mathrm{n}}=5080 \mathrm{MW}$.

However, there is $\cos \theta<1$ in practical engineering in general. Meanwhile, it has been obtained that both $U_{\mathrm{m}}^{*}$ and $I_{\mathrm{m}}$ decrease with $\cos \theta$. That is, the decrease of the power factor raises the risk of overvoltage. Therefore, to avoid power-frequency overvoltage, it is necessary to set a limit on the power factor according to the power load, as shown in Figure 5. For example, $\cos \theta$ is needed to be controlled above 

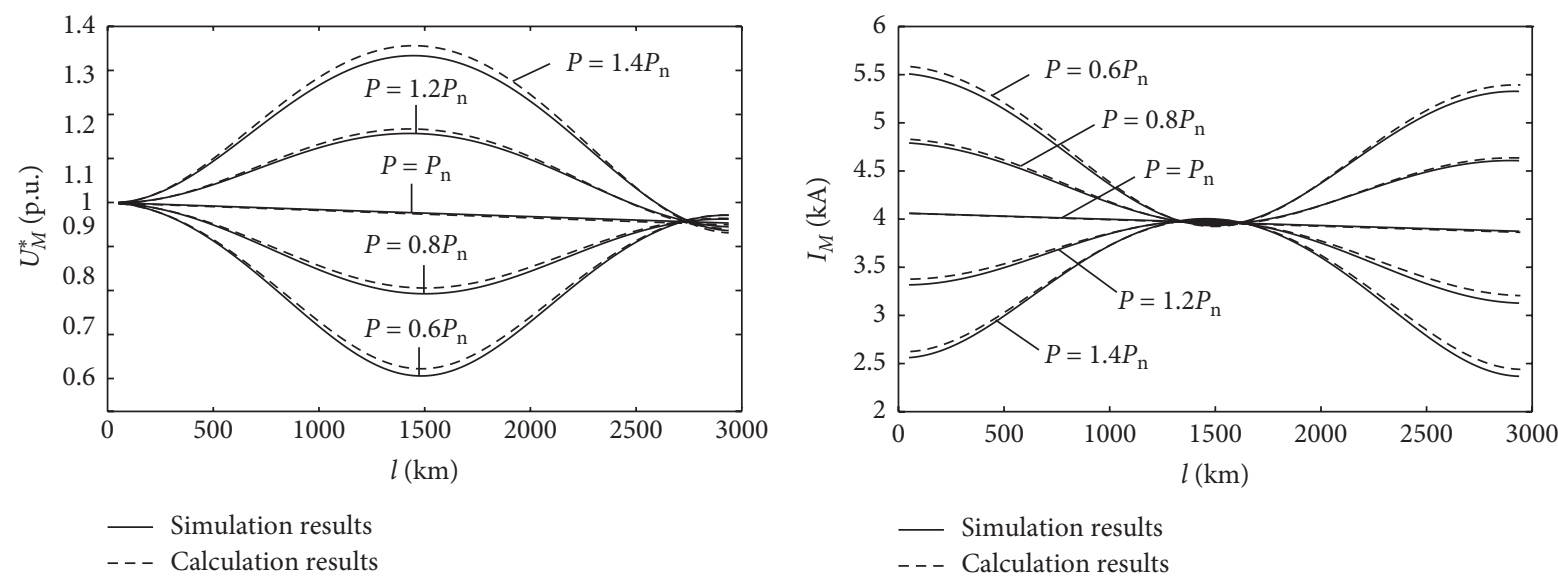

(a)

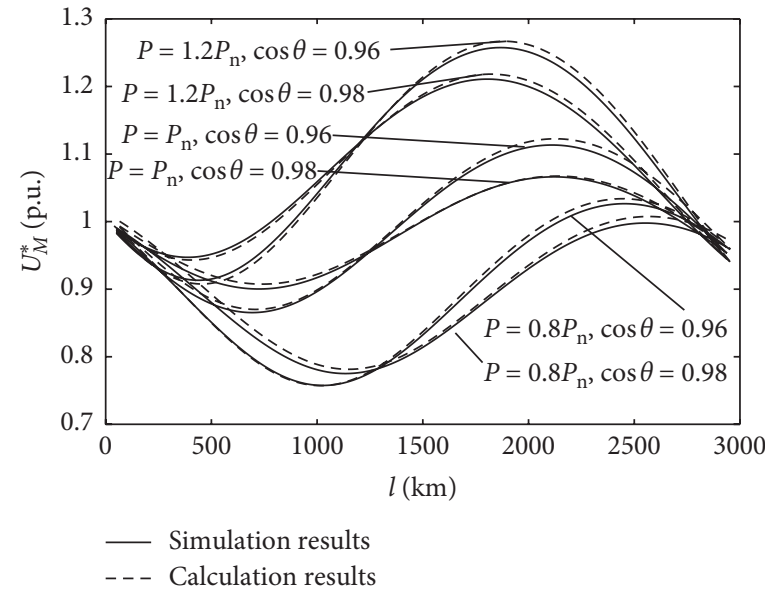

(c)

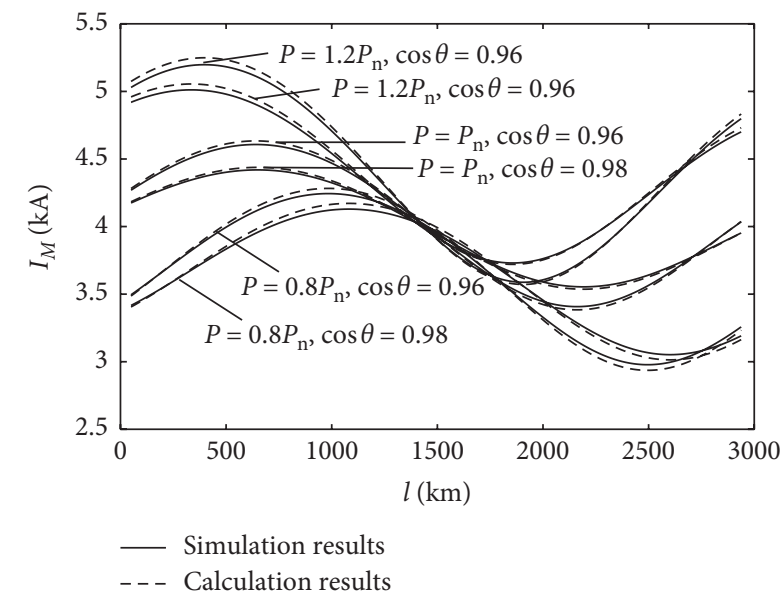

(d)

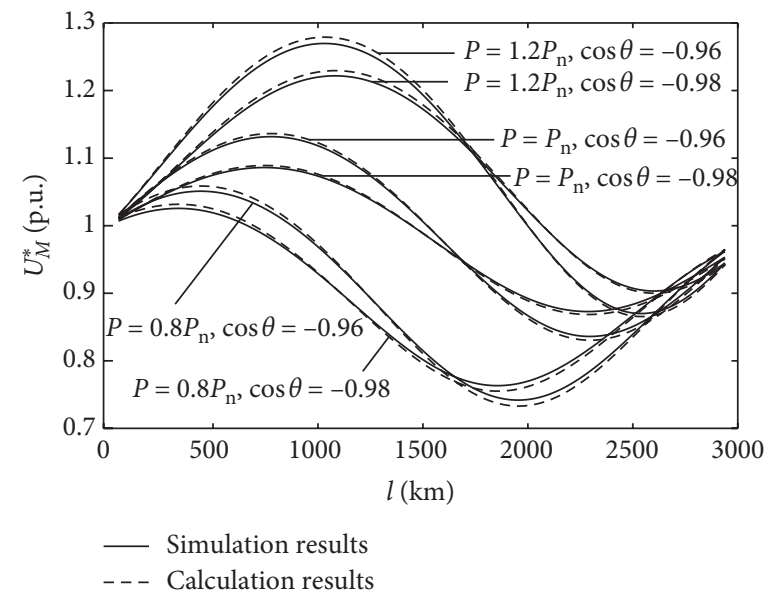

(e)

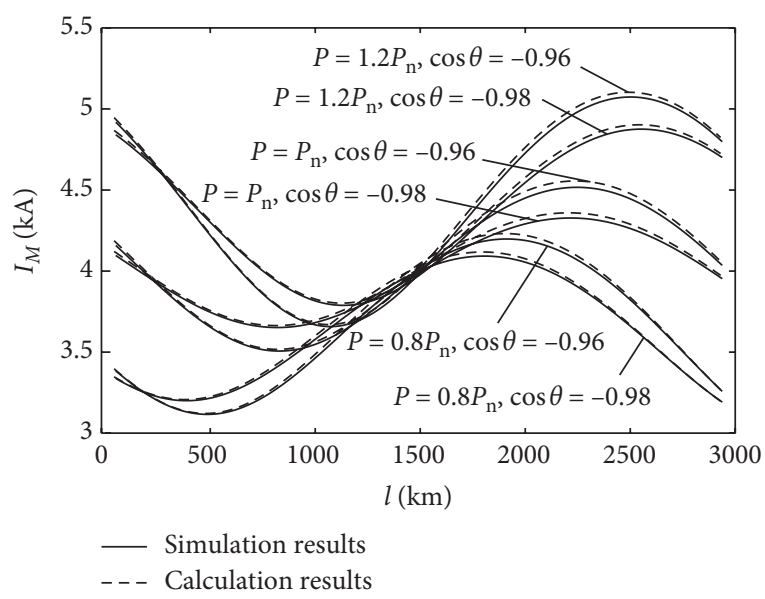

(f)

Figure 4: Distribution of power-frequency waves along the HWTL in the steady state under different operation conditions: (a) $\theta=0$. (b) $\theta=0$. (c) $\theta>0$. (d) $\theta>0$. (e) $\theta<0$. (f) $\theta<0$.

0.86 when $P=0.9 P_{\mathrm{n}}=3660 \mathrm{MW}$. Hence, the operating modes with $P<3660 \mathrm{MW}$ and $\cos \theta>0.86$ are safety for the system.

Generally, 0.85 is considered as the minimum acceptable power factor for AC transmission. Therefore, the safe operating modes are shown in the shadow area of Figure 5. It can be seen that keeping the power factor larger than 0.98 and the active power less than $5000 \mathrm{MW}$ can eliminate the power-frequency voltage. However, it is challenge for a UHV power system to keep such a large power factor. Thus, the improvement of the power factor for UHV systems is significantly important for HWTLs to put into practice. 


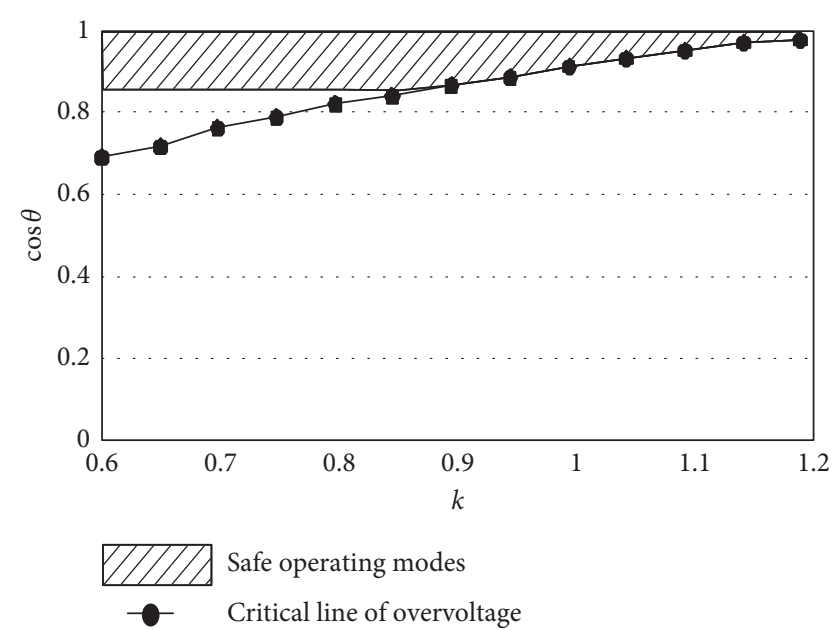

Figure 5: The safe operating modes and overvoltage operating modes.

\subsection{Analysis of Short Circuit Fault}

6.2.1. Symmetrical Short Circuit. In order to analyze the power-frequency resonance characteristics after the threephase short-circuit fault, the half-wavelength transmission system is built in the electromagnetic transient simulation program PSCAD, as shown in Figure 3. The distributed Bergeron model is also used here as a reference due to its correctness for the calculation of the conditions related to power frequency.

In this case, the HWTL is short to ground with no resistance $\left(R_{\mathrm{f}}=10^{-19} \Omega\right)$, low resistance $\left(R_{\mathrm{f}}=5 \Omega\right)$, and high resistance $\left(R_{\mathrm{f}}=50 \Omega\right)$. The condition of $R_{\mathrm{f}}=100 \Omega$ is also analyzed as a supplement. Figure 6 shows the simulation results of the maximum voltage $U_{\mathrm{Mf}}^{*}$ and short-circuit current $I_{\mathrm{Mf}}$ on the line with different fault locations $L$. Among these, except for $Z_{\mathrm{G}}$ within the general range in practice $(i 0.002 \Omega \sim i 0.07 \Omega), Z_{\mathrm{G}}=i 0.2 \Omega$ and $Z_{\mathrm{G}}=i 1 \Omega$ are also analyzed to find out the characteristics as a whole.

It can be seen from Figure 6 that when $Z_{\mathrm{G}}$ increases from $i 0.002 \Omega$ to $i 0.07 \Omega$, both $U_{\mathrm{fm}}^{*}$ and $I_{\mathrm{fm}}$ increase. However, they drop with $Z_{\mathrm{G}}$ when $Z_{\mathrm{G}}>i 0.07 \Omega$. When the system runs in the minimum operating mode $\left(Z_{\mathrm{G}}=i 0.07 \Omega\right), U_{\mathrm{fm}}^{*}$ reaches the maximum value of 21 p.u. and $I_{\mathrm{fm}}$ reaches to $90 \mathrm{kA}$. Therefore, to limit the power-frequency voltage resonance and the short-circuit current, the system shall be operated in the mode as large as possible.

In addition, $U_{\mathrm{fm}}^{*}$ and $I_{\mathrm{fm}}$ decrease significantly with the fault resistance $R_{\mathrm{f}}$. On the contrary, $L_{\mathrm{m}}$ is independent on $R_{\mathrm{f}}$. It only decreases with $Z_{\mathrm{G}}$. Even so, $L_{\mathrm{m}}$ is always larger than $\lambda_{0} / 4=1469 \mathrm{~km}$, regardless of the value of $R_{\mathrm{f}}$. Moreover, it is worth mentioning that the most serious fault overvoltages are accompanied by the maximum short-circuit currents. In other words, the most serious overvoltages and maximum short-circuit currents for HWTLs occur at the same time. This characteristic makes the short-circuit consequence of HWTLs much more serious.

To conclude, the most serious short-circuit point is mainly related to $R_{\mathrm{f}}$ rather than $Z_{\mathrm{G}}$. Considering the range

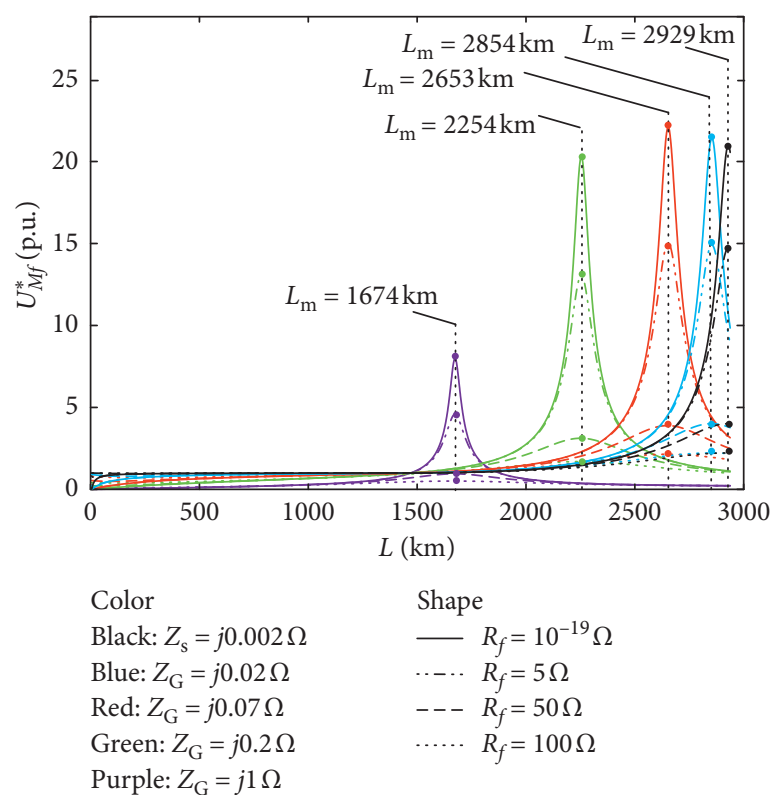

(a)

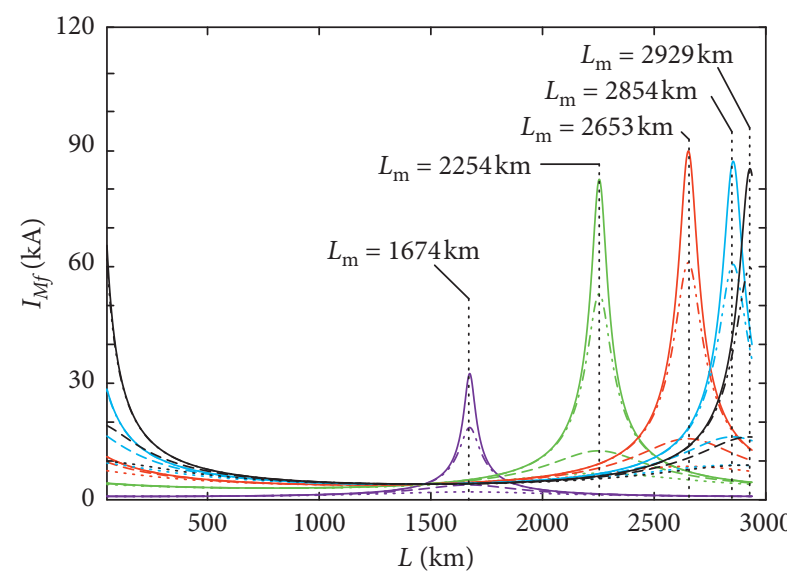

$$
\begin{aligned}
& \text { Color Shape } \\
& \text { Black: } Z_{\mathrm{s}}=j 0.002 \Omega \quad-R_{f}=10^{-19} \Omega \\
& \text { Blue: } Z_{\mathrm{G}}=j 0.02 \Omega \quad \ldots-\cdot R_{f}=5 \Omega \\
& \text { Red: } Z_{\mathrm{G}}=j 0.07 \Omega \quad---R_{f}=50 \Omega \\
& \text { Green: } Z_{\mathrm{G}}=j 0.2 \Omega \quad \ldots \ldots R_{f}=100 \Omega
\end{aligned}
$$

Purple: $Z_{\mathrm{G}}=j 1 \Omega$

(b)

Figure 6: Characteristics of the maximum voltage and current after the short-circuit fault with different fault locations. (a) Voltage; (b) current.

of $Z_{\mathrm{G}}$ and $R_{\mathrm{f}}$ in practice, it is at the distance of about $2653 \mathrm{~km} \sim 2929 \mathrm{~km}$ from the sending bus. In addition, $U_{\mathrm{fm}}^{*}$ and $I_{\mathrm{fm}}$ can reach about $4 \sim 21$ p.u. and $16 \sim 90 \mathrm{kA}$, respectively. The potential overvoltages and maximum short-circuit currents are far larger than the standard. Both of them need further analysis for the specific suppress strategies.

Considering the actual operation of the system (i0.002 $<Z_{\mathrm{G}}<i 0.07 \Omega$ and $R_{\mathrm{f}}<50 \Omega$ ), the voltage distribution on a HWTL after the most serious short circuit are analyzed, as shown in Figure 7 . In addition, the 


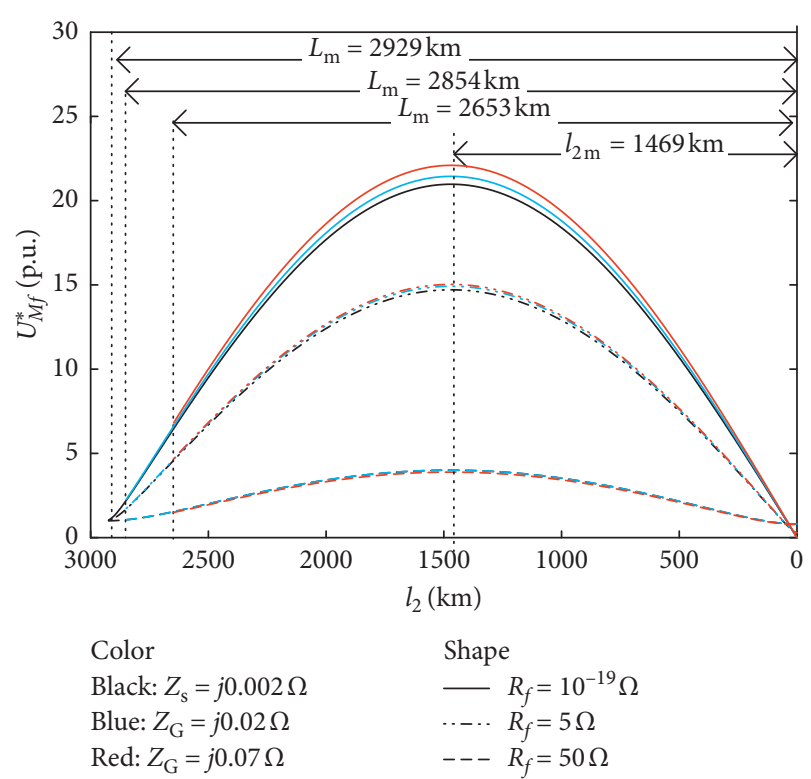

Figure 7: The voltage distribution along lines after the most serious short-circuit fault.

comparison between the simulation and calculation results are shown in Table 2.

To confirm the results above, the following are some supplemental cases, as shown in Table 3. Case A is simulated with the single-phase distributed parameter line model in DigSILENT/Power factory, while Case B uses the threephase distributed parameter line model in MATLAB/ Simulink. In addition, Case $\mathrm{C}$ is simulated in PSCAD, and the data on the steady state is collected. In this case, the frequency dependent model of the transmission line in PSCAD is used. This model is one of the most accurate model of the transmission line models, which is able to represent all the frequency-dependent effects of transmission lines.

It can be seen that the calculation results in Table 2 are fairly close to that shown in Case A and B. That is, the distributed Bergeron model can represent the distributedparameter characteristic of the line at power frequency precisely, both in the aspect of single phase and three phase. Moreover, the calculation results in Table 2 also have a good accuracy compared with Case C. It shows that the Bergeron model in PSCAD can describe the feature of lines in the steady state. However, the difference between the calculation results and Case $\mathrm{C}$ are larger than the difference between calculation results and Case A or B. The reason is that there can be a slight difference between the actual parameter in the tower line model and the calculated parameters that is used in the distributed PI models.

From the abovementioned analyses, it can be concluded that the distributed Bergeron model is accurate enough to describe the feature of transmission lines in the steady state after the short-circuit fault.
6.2.2. Asymmetrical Short Circuit. In this case, the effect of the sending system parameters and the additional impedance on the position characteristics $\left(L_{\mathrm{m}}\right.$ and $\left.l_{2 \mathrm{~m}}\right)$ for asymmetric short circuit are discussed. The PSCAD simulation results and the calculation results are shown in Table 4.

It can be obtained that the position of the most-serious fault point moves towards the midpoint of the line with the increase of the impedance of the sending system and the additional impedance. Meanwhile, the position of the maximum short-circuit voltage along the line moves from $1469 \mathrm{~km}$ to the short-circuit point with the increase of $Z_{\mathrm{f}}$. That is, the distance between the overvoltage caused by the frequency-power resonance and the sending bus is about $1184 \mathrm{~km} \sim 1460 \mathrm{~km}$. Comparing with Tables 3 and 4, it can be seen that $l_{\mathrm{m}}$ in Table 4 is approximately the same as the cases of the symmetric short circuit. In other words, it can be considered that asymmetric short circuit does not affect the positions of the most-serious overvoltage on the line. The position characteristics of the asymmetric short circuit can be analyzed by the same way as the three-phase short circuit fault.

The simulation results are consistent with the theoretical results of the proposed method. That is, the proposed algorithm can analyze the position characteristics of the mostserious asymmetric short-circuit fault. The error of the method is less than $1 \%$.

6.2.3. Voltage Distribution Characteristics of Different Length Lines. To investigate the voltage distribution characteristics for different lines, transmission lines with length of $200 \mathrm{~km}$, $500 \mathrm{~km}, 800 \mathrm{~km}, 1469 \mathrm{~km}\left(\lambda_{0} / 4\right), 2100 \mathrm{~km}$, and $2700 \mathrm{~km}$ are discussed here. Figure 8 shows both the simulation and calculation results of the voltage distribution along these lines after the most-serious short circuit, where the receiving end is assumed as an infinite-bus system.

It can be obtained that, for transmission lines longer than $1469 \mathrm{~km}$, power-frequency resonance overvoltage can occur at a distance of about $1469 \mathrm{~km}$ from the short-circuit point. However, for lines with length less than $1469 \mathrm{~km}$, there is no overvoltage along the line after short circuit.

That is to say, for any lines that is shorter than onequarter of the power-frequency wave, there is no need to worry about the issue of power-frequency overvoltage after the short circuit. However, for other lines, certain strategies are indispensable.

\section{Conclusions}

Based on the pole distribution characteristics of the FLF, the distribution of steady-state power-frequency voltage and current along HWTLs and the resonance mechanism after the fault are analyzed in this paper. The contributions are as follows: 
TABLE 2: The simulation and calculation results of the voltage and current distribution characteristics under different fault conditions for the symmetric short circuit.

\begin{tabular}{|c|c|c|c|c|c|c|c|c|c|c|}
\hline \multirow{2}{*}{\multicolumn{2}{|c|}{$\begin{array}{c}Z_{\mathrm{G}} \text { (p.u.) } \\
R_{\mathrm{f}}(\Omega)\end{array}$}} & \multicolumn{3}{|c|}{$i 0.002$} & \multicolumn{3}{|c|}{$i 0.02$} & \multicolumn{3}{|c|}{$i 0.07$} \\
\hline & & \multirow{2}{*}{$\begin{array}{l}10^{-19} \\
20.97\end{array}$} & \multirow{2}{*}{$\frac{5}{14.71}$} & \multirow{2}{*}{$\begin{array}{c}50 \\
3.89\end{array}$} & \multirow{2}{*}{$\frac{10^{-19}}{21.44}$} & \multirow{2}{*}{$\frac{5}{14.92}$} & \multirow{2}{*}{$\begin{array}{c}50 \\
4\end{array}$} & \multirow{2}{*}{$\frac{10^{-19}}{22.1}$} & \multirow{2}{*}{$\frac{5}{15.47}$} & \multirow{3}{*}{$\begin{array}{c}50 \\
4 \\
3.88\end{array}$} \\
\hline & Simulation & & & & & & & & & \\
\hline$U_{\text {fm }}$ (p.u.) & Calculation & 19.89 & 14.17 & 3.72 & 20.21 & 14.57 & 3.81 & 20.9 & 14.88 & \\
\hline \multirow{2}{*}{$I_{\mathrm{fm}}(\mathrm{kA})$} & Simulation & 85.21 & 59.73 & 15.73 & 87.11 & 60.59 & 16.2 & 89.8 & 61.03 & 16.2 \\
\hline & Calculation & 83.65 & 57.92 & 14.94 & 85.25 & 58.34 & 15.13 & 86.4 & 59.58 & 15.3 \\
\hline \multirow{2}{*}{$I_{\mathrm{fm}}(\mathrm{kA})$} & Simulation & 2929 & 2929 & 2926 & 2854 & 2854 & 2853 & 2653 & 2653 & 2650 \\
\hline & Calculation & 2929 & 2925 & 2924 & 2848 & 2848 & 2846 & 2650 & 2649 & 2646 \\
\hline \multirow{2}{*}{$L_{\mathrm{m}}(\mathrm{km})$} & Simulation & 1469 & 1469 & 1466 & 1469 & 1469 & 1468 & 1469 & 1469 & 1466 \\
\hline & Calculation & 1469 & 1469 & 1469 & 1469 & 1469 & 1469 & 1469 & 1469 & 1469 \\
\hline \multirow{2}{*}{$l_{\mathrm{m}}(\mathrm{km})$} & Simulation & 1460 & 1460 & 1460 & 1385 & 1385 & 1385 & 1184 & 1184 & 1184 \\
\hline & Calculation & 1460 & 1456 & 1455 & 1379 & 1379 & 1377 & 1181 & 1180 & 1177 \\
\hline
\end{tabular}

TABLE 3: The results of the voltage and current distribution in different cases.

\begin{tabular}{|c|c|c|c|c|c|c|c|c|c|c|}
\hline \multirow{2}{*}{\multicolumn{2}{|c|}{$\begin{array}{c}Z_{\mathrm{G}}(\text { p.u. }) \\
R_{\mathrm{f}}(\Omega)\end{array}$}} & \multicolumn{3}{|c|}{$i 0.002$} & \multicolumn{3}{|c|}{$i 0.02$} & \multicolumn{3}{|c|}{$i 0.07$} \\
\hline & & $10^{-19}$ & 5 & 50 & $10^{-19}$ & 5 & 50 & $10^{-19}$ & 5 & 50 \\
\hline \multirow{3}{*}{$U_{\mathrm{fm}}^{*}$ (p.u.) } & Case A & 20.92 & 14.70 & 3.84 & 21.39 & 14.88 & 3.96 & 22.0 & 15.42 & 3.98 \\
\hline & Case B & 20.9 & 14.72 & 3.88 & 21.25 & 14.88 & 4.02 & 21.9 & 15.29 & 3.96 \\
\hline & Case C & 21.27 & 14. 95 & 3.96 & 21.58 & 15.24 & 4 & 22.43 & 15.87 & 4. \\
\hline \multirow{3}{*}{$I_{\mathrm{fm}}(\mathrm{kA})$} & Case A & 85.16 & 59.65 & 15.62 & 87.11 & 60.53 & 16.12 & 89.69 & 60.93 & 16.13 \\
\hline & Case B & 85.13 & 59.68 & 15.64 & 87.02 & 60.51 & 16.19 & 89.61 & 60.86 & 16.1 \\
\hline & Case C & 85.11 & 58.88 & 15.63 & 87.19 & 60.66 & 16.25 & 89.76 & 61.13 & 16.22 \\
\hline \multirow{3}{*}{$I_{\mathrm{fm}}(\mathrm{kA})$} & Case A & 2929 & 2929 & 2926 & 2854 & 2854 & 2853 & 2653 & 2653 & 2650 \\
\hline & Case B & 2929 & 2928 & 2926 & 2855 & 2855 & 2853 & 2652 & 2651 & 2650 \\
\hline & Case C & 2930 & 2930 & 2927 & 2858 & 2857 & 2854 & 2655 & 2655 & 2650 \\
\hline \multirow{3}{*}{$L_{\mathrm{m}}(\mathrm{km})$} & Case A & 1469 & 1469 & 1466 & 1469 & 1469 & 1468 & 1469 & 1469 & 1466 \\
\hline & Case B & 1468 & 1468 & 1466 & 1469 & 1468 & 1468 & 1469 & 1468 & 1466 \\
\hline & Case C & 1469 & 1469 & 1466 & 1469 & 1469 & 1465 & 1470 & 1470 & 1462 \\
\hline \multirow{3}{*}{$l_{\mathrm{m}}(\mathrm{km})$} & Case A & 1460 & 1460 & 1460 & 1385 & 1385 & 1385 & 1184 & 1184 & 1184 \\
\hline & Case B & 1461 & 1460 & 1460 & 1386 & 1387 & 1385 & 1183 & 1183 & 1184 \\
\hline & Case C & 1461 & 1461 & 1461 & 1389 & 1388 & 1389 & 1185 & 1185 & 1188 \\
\hline
\end{tabular}

TABLE 4: The simulation and calculation results of the voltage and current distribution for asymmetric short circuit.

\begin{tabular}{|c|c|c|c|c|c|c|c|c|c|c|}
\hline \multirow{2}{*}{\multicolumn{2}{|c|}{$\begin{array}{c}Z_{\mathrm{G}} \text { (p.u.) } \\
\mathrm{Z}_{\mathrm{f}} \text { (p.u.) }\end{array}$}} & \multicolumn{3}{|c|}{$i 0.002$} & \multicolumn{3}{|c|}{$i 0.02$} & \multicolumn{3}{|c|}{$i 0.07$} \\
\hline & & \multirow{2}{*}{$\frac{0.001}{2925}$} & \multirow{2}{*}{$\begin{array}{c}0.01 \\
2887\end{array}$} & \multirow{2}{*}{$\frac{0.1}{2535}$} & \multirow{2}{*}{$\begin{array}{l}0.001 \\
2850\end{array}$} & \multirow{2}{*}{$\frac{0.01}{2812}$} & \multirow{2}{*}{$\frac{0.1}{2460}$} & \multirow{2}{*}{$\frac{0.001}{2649}$} & \multirow{2}{*}{$\begin{array}{c}0.01 \\
2611\end{array}$} & \multirow{2}{*}{$\frac{0.1}{2259}$} \\
\hline & Simulation & & & & & & & & & \\
\hline$L_{\mathrm{m}}(\mathrm{Km})$ & Calculation & 2920 & 2872 & 2528 & 2841 & 2802 & 2455 & 2645 & 2605 & 2253 \\
\hline \multirow{2}{*}{$l_{2 \mathrm{~m}}(\mathrm{~km})$} & Simulation & 1465 & 1427 & 1075 & 1465 & 1427 & 1075 & 1465 & 1427 & 1075 \\
\hline & Calculation & 1465 & 1425 & 1074 & 1465 & 1425 & 1069 & 1465 & 1425 & 1069 \\
\hline \multirow{2}{*}{$l_{\mathrm{m}}(\mathrm{km})$} & Simulation & 1460 & 1460 & 1460 & 1385 & 1385 & 1385 & 1184 & 1184 & 1184 \\
\hline & Calculation & 1455 & 1453 & 1452 & 1376 & 1373 & 1374 & 1180 & 1176 & 1172 \\
\hline
\end{tabular}

(1) The influence of load power and power factor on the distribution of steady-state power-frequency voltage and current along the line under the steady state is analyzed. It is proved theoretically that the increase of load power or the decrease of the power factor will increase the maximum voltage and current along the line. To reduce the risk of power-frequency overvoltage for a HWTL in practice, it is necessary to keep the load power less than 1.2 times of natural power.
(2) The method reveals the mechanism of steady-state power-frequency resonance for the symmetrical short circuit, which considers both the system parameters and fault condition simultaneously. The results show that, when a HWTL is short circuited at a distance of $2640 \mathrm{~km} \sim 2930 \mathrm{~km}$ from the sending bus, there can be an overvoltage that reaches up to 21 p.u. caused by power-frequency resonance. Meanwhile, the overvoltage occurs at a distance of $1469 \mathrm{~km}$ from the fault point. 


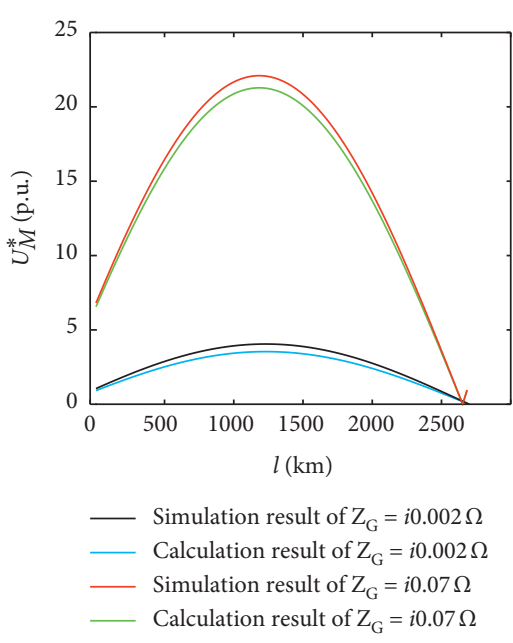

(a)

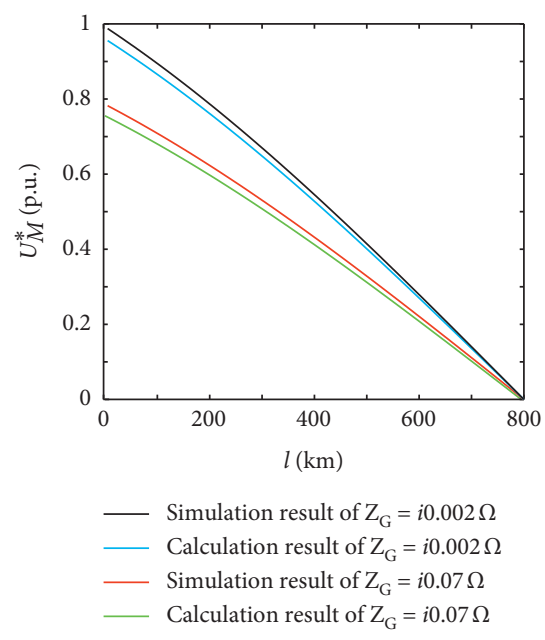

(d)

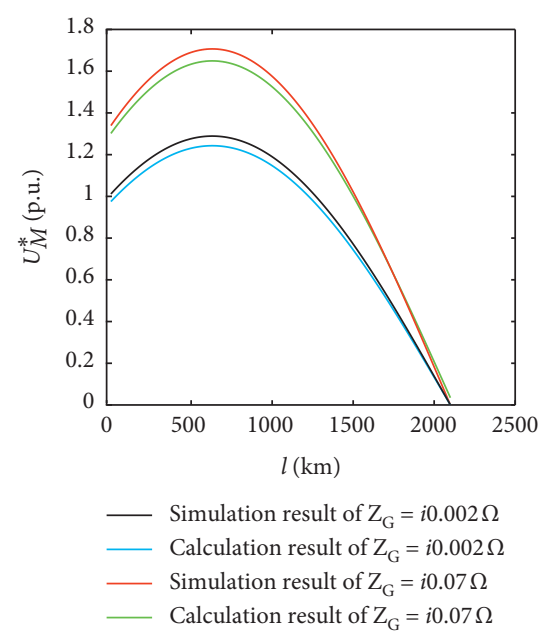

(b)

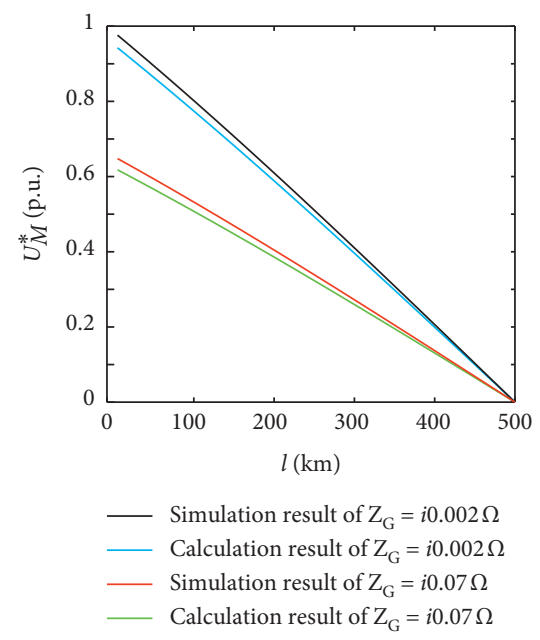

(e)

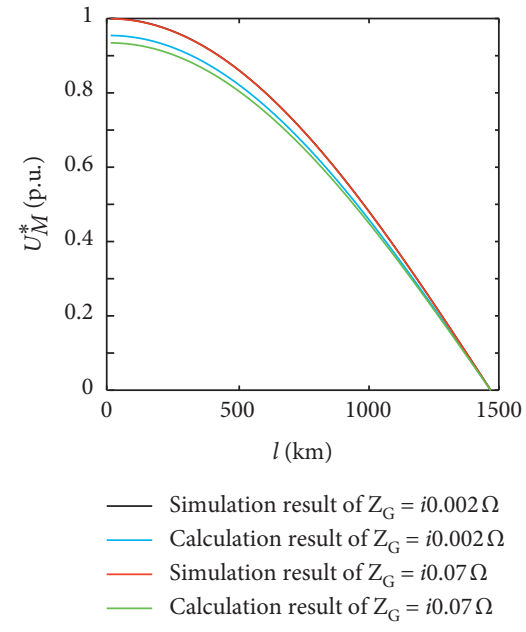

(c)

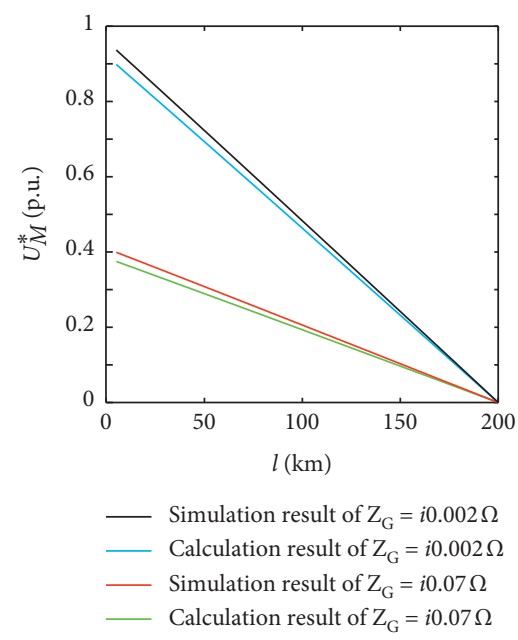

(f)

Figure 8: The voltage distribution along lines after the most-serious short-circuit fault for different lines $\left(R_{\mathrm{f}}=10^{-19} \Omega\right)$. (a) $L=2700 \mathrm{~km}$; (b) $L=2100 \mathrm{~km}$; (c) $L=1469 \mathrm{~km}$; (d) $L=800 \mathrm{~km}$; (e) $L=500 \mathrm{~km}$; (f) $L=200 \mathrm{~km}$.

(3) The fault point that leads to the most serious asymmetric short circuit moves towards the midpoint of the line with the increase of the sending system impedance or additional impedance. And the position of the maximum short-circuit voltage on the line moves from $1469 \mathrm{~km}$ to the short circuit points only with the increase of the additional impedance.

(4) Based on the algorithm, it is proved theoretically that for lines with length less than $1469 \mathrm{~km}$, there is no steady-state power-frequency resonance and overvoltage in theory, no matter what the system and fault conditions are.

(5) Based on the proposed method, the position and amplitude of the maximum power-frequency voltage and current of the HWTL can be analyzed accurately. The simulation results verify its high applicability and accuracy.

\section{Data Availability}

The data used to support the findings of this study are included within the article.

\section{Additional Points}

Recommendations. With the increasing integration of renewable energy sources [34], the impact of the power electronic converters should be considered in future analysis. Many research studies have been carried out to investigate the stability issues for the power system with converters [35-37]. Combining the FLF-based method with them could be a potential approach for analyzing the impact of converters.

\section{Conflicts of Interest}

The authors declare that there are no conflicts of interest regarding the publication of this paper.

\section{Acknowledgments}

This work was supported in part by the National Natural Science Foundation of China (Grant no. 51877141). The 
National Natural Science Foundation of China (Grant no. 51477105) has funded this research.

\section{References}

[1] Z. Xu, J. Yang, and N. Sheng, "Infeasibility analysis of halfwavelength transmission systems," Energies, vol. 11, no. 7, p. 1790, 2018.

[2] C. Chen, H. Yang, W. Wang, M. Mandich, W. Yao, and Y. Liu, "Harmonic transmission characteristics for ultra-long distance AC transmission lines based on frequency-length factor," Electric Power Systems Research, vol. 182, Article ID 106189, 2020.

[3] J. S. Ortega and M. C. Tavares, "New perspectives about AC link based on half-wavelength properties for bulk power transmission with flexible distance," IET Generation, Transmission \& Distribution, vol. 12, no. 12, pp. 3005-3012, 2018.

[4] C. Pulin, S. Hongchun, Y. Bo et al., "Voltage distribution-based fault location for half-wavelength transmission line with large-scale wind power integration in China," Energies, vol. 11, p. 593, 2018.

[5] Y. Wei, Z. Zheng, Y. Sun, Z. Wei, and G. Sun, "Voltage stability bifurcation analysis for AC/DC systems with VSCHVDC," Abstract and Applied Analysis, vol. 2013, Article ID 387167, 9 pages, 2013.

[6] Y. Chen and X. Zhang, "Voltage balancing method on expert system for 51-level MMC in high voltage direct current transmission," Mathematical Problems in Engineering, vol. 2016, Article ID 2968484, 6 pages, 2016.

[7] T. T. Qian and S. H. Miao, "Discrete-time nonlinear control of VSC-HVDC system," Mathematical Problems in Engineering, vol. 2015, Article ID 929467, 11 pages, 2015.

[8] H. Xie, B. Wan, and J. Zhang, "Outliers analysis of RI longterm data in fair weather from $1000 \mathrm{kV}$ UHV AC power lines," IEEE Transactions on Power Systems, vol. 34, no. 4, pp. 3277-3279, 2019.

[9] R. G. F. Espinoza and M. C. Tavares, "Faulted phase selection for half-wavelength power transmission lines," IEEE Transactions on Power Delivery, vol. 33, no. 2, pp. 992-1001, 2018.

[10] M. L. dos Santos, J. A. Jardini, R. P. Casolari et al., "Power transmission over long distances: economic comparison between HVDC and half-wavelength line," IEEE Transactions on Power Delivery, vol. 29, no. 2, pp. 502-509, 2014.

[11] Y. Wang, X. Song, and Y. Zhang, "Study on the Influence factors of Submersible Arc of Half Wavelength AC Transmission Line," in Proceedings of the 2018 International Conference on Electronics Technology (ICET), pp. 257-261, Chengdu, China, May 2018.

[12] L. Wang, Y. Hu, X. Shi et al., "A single-ended fault location method based on distributed parameter model for halfwavelength AC transmission line," in Proceedings of the 2018 2nd IEEE Conference on Energy Internet and Energy System Integration (EI2), pp. 1-5, Beijing, China, October 2018.

[13] L. Qiu, L. Li, C. Li et al., "Study on the steady-state reactive power compensation of half-wavelength transmission lines considering the influences of the equivalent power supply impedance," in Proceedings of the 2017 12th IEEE Conference on Industrial Electronics and Applications (ICIEA), pp. 860865, Siem Reap, Cambodia, June 2017.

[14] L. C. F. Gomes, L. C. P. D. Silva, and M. C. Tavares, "Halfwavelength transmission lines for connecting power plants in Amazon region to the Brazilian system," in Proceedings of the 2013 IEEE Grenoble Conference, pp. 1-6, Grenoble, France, June 2013.
[15] R. Dias, A. Lima, C. Portela, and M. Aredes, "Extra longdistance bulk power transmission," IEEE Transactions on Power Delivery, vol. 26, no. 3, pp. 1440-1448, 2011.

[16] O. Dias and M. C. Tavares, "Single-phase auto-reclosing mitigation procedure for half-wavelength transmission line," IET Generation, Transmission \& Distribution, vol. 11, no. 17, pp. 4324-4331, 2017.

[17] T. Li, Y. Li, M. Liao, W. Wang, and C. Zeng, "A new wind power forecasting approach based on conjugated gradient neural network," Mathematical Problems in Engineering, vol. 2016, pp. 1-8, 2016.

[18] X. Deng, H. Li, W. Yu, W. Weikang, and Y. Liu, "Frequency observations and statistic analysis of worldwide main power grids using FNET/GridEye," in Proceedings of the IEEE Power \& Energy Society General Meeting, Atlanta, GA, USA, August 2019.

[19] Y. Wang, W. Xu, Y. W. Li, and T. Hao, "High-frequency, halfwavelength power transmission scheme," IEEE Transactions on Power Delivery, vol. 32, no. 1, pp. 279-284, 2017.

[20] H. Xu, R. Zhang, X. Li, and Y. Yan, "Fault tripping criteria in stability control device adapting to half-wavelength AC transmission line," IEEE Transactions on Power Delivery, vol. 34, no. 4, pp. 1619-1625, 2019.

[21] Z. Zhang, X. Qin, H. Wang, and Z. Xu, "Steady state voltage characteristic of UHV half-wavelength AC transmission line," Power System Technology, vol. 35, pp. 33-36, 2011.

[22] L. Wang and X. Cui, "Research on steady-state operation characteristics of UHV half-wavelength AC power transmission line," Power System Technology, vol. 35, pp. 7-12, 2011.

[23] P. Nan, C. Menghan, L. Rui, and F. Zare, "Asynchronous fault location scheme for half-wavelength transmission lines based on propagation characteristics of voltage travelling waves," IET Generation, Transmission \& Distribution, vol. 13, no. 4, pp. 502-510, 2019.

[24] N. Tong, L. Chen, W. Wang, X. Lin, and Z. Li, "Local-measurement-based high-speed protection for half-wavelength UHV lines," IEEE Transactions on Power Delivery, Article ID 2969960, 2020.

[25] Q. Zhang, C. Li, and L. Wan, "Research on resonance point of three-phase short circuit fault on half-wavelength AC transmission lines," Power System Technology, vol. 41, pp. 2743-2748, 2017.

[26] H. Tian, Y. Liu, D. Yang et al., "Voltage characteristic analysis of UHV half-wavelength AC transmission system," High Voltage Engineering, vol. 44, pp. 83-89, 2018.

[27] C. Chen, H. Yang, and M. Tan, "Harmonic transmission characteristic analysis of non-standard half-wavelength AC transmission line," Power System Technology, vol. 42, pp. 1580-1587, 2018.

[28] H. Zhou, W. Qiu, K. Sun et al., Ultra High Voltage AC/DC Power Transmission, Springer, Berlin, Germany, 1st edition, 2018.

[29] Nanjing Nanrui Jibao Electric Co and National Dispatch Center, "Relay protection of $1000 \mathrm{kV}$ AC transmission system," in Proceedings of the 2008 Chinese Society for Electrical Engineering, Xi an, China, November, 2008.

[30] F. Wang, "Probabilistic safety analysis of transmission system and its application in emergency control," M.S. dissertation, Tian Jin University, Tian Jin, China, 2006.

[31] X. Qin, Z. Zhang, Z. Xu et al., "Study on the steady state characteristic and transient stability of UHV AC half-wavelength transmission system based on quasi-steady model," Proceedings of the Chinese Society for Electrical Engineering, vol. 31, pp. 66-76, 2011. 
[32] J. Le and R. Hu, PSCAD X4 Circuit Design and Simulation from Introduction to Proficiency, vol. 1, pp. 208-209, Chian Machine Press, Beijing, China, 2015.

[33] P. Meng, Y. Zhou, and J. Wu, "Surge arrester with high performance metal oxide varistors for deeply suppressing overvoltage in AC UHV systems," in Proceedings of the 2018 IEEE International Conference on High Voltage Engineering and Application (ICHVE), pp. 1-4, Athens, Greece, September 2018.

[34] W. Yao, S. You, W. Wang et al., "A fast load control system based on mobile distribution-level phasor measurement unit," IEEE Transactions on Smart Grid, vol. 11, no. 1, pp. 895-904, 2020.

[35] R. Wang, Q. Sun, D. Ma, and Z. Liu, "The small-signal stability analysis of the droop-controlled converter in electromagnetic timescale," IEEE Transactions on Sustainable Energy, vol. 10, no. 3, pp. 1459-1469, 2019.

[36] X. Wang and F. Blaabjerg, "Harmonic stability in power electronic-based power systems: concept, modeling, and analysis," IEEE Transactions on Smart Grid, vol. 10, pp. 2858-2870, 2018.

[37] A. Korai and I. Erlich, "The harmonic stability problem in offshore wind farms and targeted extension of the HVDC link control for its mitigation," IFAC-papers onLine, vol. 49, no. 27, pp. 19-27, 2019. 